\title{
Aplikasi Prediksi Penjualan Kopi dengan Metode Single Exponential Smoothing untuk Mengetahui Produk Kopi Terlaris
}

\author{
Robby Yuli Endra*, Oktavia Laurina \\ Program Studi Informatika, Fakultas Ilmu Komputer, \\ Universitas Bandar Lampung \\ Lampung, INDONESIA \\ robbyyuliendra@ubl.ac.id*,oktavia.17421032@student.ubl.ac.id
}

\begin{abstract}
Indonesia is the fourth-largest coffee exporter in the world. for the Indonesian state, it only focuses on quantity, in fact, the quality of Indonesian coffee has been recognized by various parties in various countries. The majority of the Indonesian population likes coffee, especially the people of Lampung, but only with certain types of coffee such as Arabica, Robusta, etc. Therefore, coffee sellers must provide a stock of various types of coffee products. In the supply of coffee products with various types, it can cause difficulties in providing coffee products and effective storage so that the existing products are preserved and the quality of taste is maintained. The provision of coffee products is carried out using estimates without any definite calculations and also the seller has not been able to predict the coffee products that are often in demand by consumers. Based on the problems experienced, we need a method that is able to predict the coffee products that will be sold a lot, so that there is no accumulation of product stock. One method that can help solve this problem is to use the single exponential smoothing method. Single exponential smoothing is one of the existing methods in the forecasting (prediction) system. By looking at the problems and methods that have been determined to solve the problems, this research will build a forecasting application (prediction). This system can help sellers in predicting coffee product sales. So that sellers can find out which coffee products will be selling well and can prepare the amount of coffee availability that customers are interested in.
\end{abstract}

Keywords: Coffee; Single Exponential Smoothing; Prediction; Bestsellers.

Abstrak - Indonesia merupakan pengekspor kopi terbesar keempat di dunia. bagi negara Indonesia hal tersebut hanya berfokus ke kuantitas saja pada kenyataannya kualitas kopi Indonesia sudah di akui dari berbagai pihak di beragam negara. Mayoritas penduduk Indonesia yang menyukai kopi khususnya masyarakat Lampung, tetapi hanya dengan jenisjenis kopi tertentu saja misalnya arabika, robusta, dll. Oleh karena itu penjual kopi harus menyediakan stok produkproduk kopi dengan berbagai jenis. Dalam penyediaan produk kopi dengan berbagai jenis dapat menyebabkan kesulitan dalam melakukan penyediaan produk kopi dan penyimpanan yang efektif agar produk yang ada tetap terjaga keawetan nya dan terjaga kualitas dari rasa. Penyediaan produk kopi dilakukan menggunakan perkiraan tanpa adanya perhitungan yang pasti dan juga penjual belum bisa memprediksi produk kopi yang sering diminati para konsumen. Berdasarkan permasalahan yang di alami maka di perlukan suatu metode yang mampu memprediksi produk kopi yang akan banyak terjual, agar tidak terjadi penumpukan stok produk. Salah satu metode yang dapat membantu menyelesaikan permasalahan tersebut adalah menggunakan metode Single Exponential Smooting. Single Exponential Smooting ialah salah satu metode pada sistem forecasting (prediksi). Dengan melihat permasalahan dan metode yang sudah di tentukan untuk menyelesaikan permasalahan, maka pada penelitian ini akan di bangun sebuah aplikasi forecasting (prediksi). Dengan adanya sistem ini dapat membantu penjual dalam memprediksi penjualan produk kopi. Sehingga penjual dapat mengetahui produk kopi yang akan laris terjual dan dapat mempersiapkan jumlah ketersediaan kopi yang diminati para customer.

Kata Kunci: Kopi; Single Exponential Smoothing; Prediksi; Terlaris.

\section{Pendahuluan}

Indonesia merupakan pengekspor kopi terbesar keempat di dunia. Bagi negara Indonesia hal tersebut hanya berfokus ke kuantitas saja pada kenyataannya kualitas kopi Indonesia sudah di akui dari berbagai pihak di beragam negara. Sebagai komoditas andalan ekspor, kopi Indonesia sudah mampu dijadikan sebagai salah satu devisa negara. Hal ini dapat di lihat dari pembangunan perkebunan kopi yang semakin hari semakin meningkat. Dalam hal ini pembangunan perkebunan komoditas kopi di dominasi oleh perkebunan rakyat lebih dari 90\% dan sisanya dari perkebunan besar swasta atau negara sebesar $10 \%$ [1]. Mengingat besarnya potensi yang dimiliki negara Indonesia pendampingan dan penyuluhan teknologi budidaya serta pengolahan kopi sangat di perlukan bagi petani. Pendampingan dan penyuluhan ini dapat meningkat produktivitas serta kualitas kopi secara 
nasional. Hal tersebut diharapkan mampu meningkatkan daya saing komoditas di pasar dunia.

Kemajuan perkembangan kopi di Indonesia sangat signifikan. Kualitas rasa yang cukup baik dimiliki oleh kopi nusantara tersebar di berbagai daerah indonesia. Hal ini disebabkan karena kopi sangat berkembang tumbuh di kawasan beriklim tropis seperti indonesia. Bahkan sebagian daerah di Indonesia sudah termasuk penghasil kopi terbaik dan terbesar di dunia. Salah satunya pada provinsi Lampung. Provinsi Lampung memiliki luas lahan kopi sebesar $156.878 \mathrm{Ha}$ dengan produksi mencapai 110.570 ton [2]. Kopi yang dihasilkan dari provinsi lampung memiliki keistimewaan tersendiri ialah cita rasa dan wangi yang dihasilkan bisa sempurna. Hal ini di dapatkan dari perawatan dan pengelolaannya dilakukan dengan sangat insentif. Selanjutnya untuk melindungi daya jual kopi di lampung, para petani juga sudah mulai melestarikan budidaya tanaman kopi secara organik. Hal tersebut dikarenakan pecinta kopi tingkat dunia lebih berminat dengan kopi organik yang lebih sehat [3].

Mayoritas penduduk Indonesia yang menyukai kopi khususnya masyarakat Lampung, tetapi hanya dengan jenis-jenis kopi tertentu saja misalnya arabika, robusta, dan lain-lain [4]. Oleh karena itu penjual kopi harus menyediakan stok produk-produk kopi dengan berbagai jenis. Dalam penyediaan produk kopi dengan berbagai jenis dapat menyebabkan kesulitan dalam melakukan penyediaan produk kopi dan penyimpanan yang efektif agar produk yang ada tetap terjaga keawetan nya dan terjaga kualitas dari rasa. Penyediaan produk kopi dilakukan menggunakan perkiraan tanpa adanya perhitungan yang pasti. Hal ini dapat mengakibatkan kehabisan stok produk kopi ketika penjualan meningkat dan dapat pula terjadinya kelebihan stok produk apabila penjualan menurun.

Berdasarkan permasalahan yang di alami maka di perlukan suatu metode yang mampu memprediksi produk kopi yang akan banyak terjual, agar tidak terjadi penumpukan stok produk. Salah satu metode yang dapat membantu menyelesaikan permasalahan tersebut ialah memakai metode Single Exponential Smooting. Single Exponential Smooting merupakan salah satu metode yang ada dalam sistem forecasting [5]. Metode ini digunakan untuk memprediksi penjualan produk kopi dengan pola data horizontal yang tidak pasti dari waktu ke waktu. Metode ini biasanya digunakan untuk memprediksi permintaan yang perubahan nya yang sangat cepat. Metode Single Exponential Smooting sebenarnya ialah metode yang memperlihatkan pembobotan menurun secara exponential terhadap nilai observasi yang lebih tua, yaitu nilai yang lebih baru diberikan bobot relatif lebih besar dibanding nilai observasi yang lebih lama [6].

Dengan melihat permasalahan dan metode yang sudah di tentukan untuk menyelesaikan permasalahan, maka pada penelitian ini akan di bangun sebuah aplikasi forecasting. Forecasting ialah peramalan yang akan terjadi pada waktu yang akan datang [7]. Adanya sistem ini bisa menunjang penjual dalam memprediksi penjualan produk kopi. Sehingga penjual dapat mengetahui produk kopi yang akan laris terjual dan dapat mempersiapkan jumlah ketersediaan kopi yang diminati para customer.

\section{Metodologi}

\section{A. Metode Penelitian}

Metode ini diterapkan oleh penulis yang bertujuan memprediksi penjualan produk kopi dengan pola data horizontal yang tidak pasti dari waktu ke waktu. Metode ini biasanya digunakan untuk memprediksi permintaan yang perubahan nya yang sangat cepat. Metode single exponential smoothing pada hakikatnya ialah kelanjutan metode moving averages sederhana [6].

Metode Single Exponential Smooting memperlihatkan pembobotan menyusut menurut eksponensial atas tingkat pengamatan yang lebih tua. Ialah tingkat yang lebih baru memberikan bobot relatif lebih besar daripada tingkat pengamatan lebih lama. Metode membagikan suatu pembobotan eksponensial sama beralih dari segala tingkat pengamatan sebelumnya. Metode tidak mempengaruhi oleh trend maupun musim. Bagi meramalkan tingkat periode selanjutnya mesti ada data permintaan dari periode sebelumnya dan peramalan periode sebelumnya [8].

\section{B. Metode Pengumpulan Data}

Penelitian ini menggunakan 2 metode pengumpulan data yaitu Studi Pustaka (Library Research) dan Studi Lapangan (Field Research). Studi pustaka diperuntukkan untuk membantu penyusunan, melangsukan akumulasi data menggunakan panduan buku referensi, paper, website, dan literature yang berhubungan atas pengetahuan teoritis mengenai masalah yang sedang diteliti, yang kemudian dijadikan data untuk diolah lebih lanjut.

Sedangkan studi lapangan sendiri mengenai metode yang dilaksanakan pada studi lapangan yaitu observasi, wawancara, dan kepustakaan. Observasi dalam pelaksanaan bagan ini, penelitian ini masuk ke tempat observasi secara langsung guna mencermati tahap pengembangan sistem, konfirgurasi data dan perihal yang terikat dalam penelitian. Dan pemulangan data melewati wawancara secara lisan atau langsung dengan pemilik Rumah Produksi De Lampoeng Kopi, melalui tatap muka dan jawaban responden dicatat dan dirangkum peneliti yang dimasukan dalam lampiran. Guna mensupport penelitian ini membutuhkan sumber yang telah dipaparkan yaitu dengan metode kepustakaan.

\section{Hasil dan Pembahasan}

\section{A. Hasil}

Pada penelitian ini menghasilkan sebuah pembentukan sistem prediksi berbasis web yang memakai metode Single Exponential Smooting serta dipakai untuk memprediksi penjualan kopi terlaris. Implementasi metode Single Exponential Smooting ada jumlah tingkatan yang dilakukan dalam penelitian, yaitu mengindentifikasi masalah, perhitungan data sebelumnya, meliputi penentuan nilai alpha $(\alpha)$, menentukan nilai Ft dengan data yang sebelumnya.

Sistem ini diterima oleh 2 user yaitu user admin dan user pembeli, user admin diperoleh menu prediksi yang 
menciptakan sebuah tampilan grafik dimana penjual (admin) dapat meninjau hasil prediksi penjualan selanjutnya. Bersama itu user admin dapat mengelola data penjualan kopi, user admin juga dapat meninjau data transaksi user atau pembeli. Berikutnya pada user pembeli terdapat halaman belanja dimana pembeli bisa membeli produk kopi tersebut, selain itu pada user pembeli juga terdapat menu keranjang pembelian yang dimana user pembeli bisa melihat pesanan yang mereka pilih, dan pada user pembeli terdapat menu checkout yang dimana user pembeli dapat melihat produk yang dibeli, harga, jumlah pembelian, menu yang terakhir yaitu menu transaksi dimana user pembeli dapat melihat status pemesanan.

\section{B. Pembahasan}

Metode Single Exponential Smooting merupakan metode suatu pembobotan eksponensial rata-rata bergerak pada semua nilai sebelumnya. Pada metode ini tidak dipengaruhi oleh trend maupun musim. Bagi meramalkan nilai periode berikutnya diperlukan data permintaan dari periode sebelumnya dan peramalan periode sebelumnya [9].

Proses perhitungan metode Single Exponential Smoothing adalah sebagai berikut:

$$
\begin{array}{ll} 
& F t=F(t-1)+\alpha(A(t-1)-F(t-1)) \\
\text { Dimana: } & \\
\alpha & =\text { Konstanta } \\
A(t-1) & =\text { Nilai aktual periode sebelumnya } \\
F(t-1) & =\text { Ramalan sebelumnya } \\
F t & =\text { Ramalan baru. }
\end{array}
$$

Tabel 1. Data Kopi

\begin{tabular}{lrr}
\hline Bulan & Tahun & Data Actual \\
\hline Januari & 2020 & 120 \\
Februari & 2020 & 95 \\
Maret & 2020 & 110 \\
April & 2020 & 85 \\
Mei & 2020 & 90 \\
Juni & 2020 & 90 \\
Juli & 2020 & 100 \\
Agustus & 2020 & 140 \\
September & 2020 & 145 \\
Oktober & 2020 & 135 \\
November & 2020 & 125 \\
Desember & 2020 & 100 \\
Januari & 2021 & 90 \\
Februari & 2021 & 75 \\
Maret & 2021 & 85 \\
April & 2021 & 95 \\
Mei & 2021 & 70 \\
Juni & 2021 & 60 \\
Juli & 2021 & 65 \\
Agustus & 2021 & 50 \\
September & 2021 & 0 \\
Oktober & 2021 & 0 \\
November & 2021 & 0 \\
Desember & 2021 & 0 \\
\hline
\end{tabular}

1) Perhitungan Peramalan di Tahun 2020

Pada tahap pertama ini adalah penentuan nilai alpha $(\alpha)$. Pada dasarnya dalam menentukan nilai alpha ditentukan dari rentang 0.1 sampai 0.9 yang akan digunakan untuk menghitung prediksi. Pada penelitian ini menggunakan nilai alpha 0,9 karena nilai tersebut dinilai lebih akurat [10]. Pada tahap kedua adalah menentukan nilai Ft dengan data yang sebelumnya.

Berikut perhitungan peramalan di tahun 2020:

a. Peramalan untuk bulan 1 , ditentukan sebesar nilai actual rill bulan januari 2021 yaitu 120 .

b. Peramalan untuk bulan 2, yaitu:

$$
\begin{aligned}
\mathrm{F}_{\mathrm{t}} & =\mathrm{F}_{(\mathrm{t}-1)}+\alpha\left(\mathrm{A}_{\mathrm{t}-1)}-\mathrm{F}_{(\mathrm{t}-1)}\right) \\
& =120+0,9(120-120) \\
& =120,9
\end{aligned}
$$

c. Peramalan untuk bulan 3, yaitu:

$$
\begin{aligned}
\mathrm{F}_{\mathrm{t}} & =\mathrm{F}_{(\mathrm{t}-1)}+\alpha\left(\mathrm{A}_{(\mathrm{t}-1)}-\mathrm{F}_{(\mathrm{t}-1)}\right) \\
& =120,9+0,9(95-120,9) \\
& =97,59
\end{aligned}
$$

d. Peramalan untuk bulan 4, yaitu:

$$
\begin{aligned}
\mathrm{F}_{\mathrm{t}} & =\mathrm{F}_{(\mathrm{t}-1)}+\alpha\left(\mathrm{A}_{(\mathrm{t}-1)}-\mathrm{F}_{(\mathrm{t}-1)}\right) \\
& =97,59+0,9(110-97,59) \\
& =108,
\end{aligned}
$$

e. Peramalan untuk bulan 5, yaitu:

$$
\begin{aligned}
\mathrm{F}_{\mathrm{t}} & =\mathrm{F}_{(\mathrm{t}-1)}+\alpha\left(\mathrm{A}_{(\mathrm{t}-1)}-\mathrm{F}_{(\mathrm{t}-1)}\right) \\
& =108,7+0,9(85-108,7) \\
& =87,37
\end{aligned}
$$

f. Peramalan untuk bulan 6, yaitu:

$$
\begin{aligned}
\mathrm{F}_{\mathrm{t}} & =\mathrm{F}_{(\mathrm{t}-1)}+\alpha\left(\mathrm{A}_{(\mathrm{t}-1)}-\mathrm{F}_{(\mathrm{t}-1)}\right) \\
& =87,37+0,9(90-87,37) \\
& =89,737
\end{aligned}
$$

DOI http://dx.doi.org/10.36448/expert.v11i2.2212 e-ISSN 2745-7265 p-ISSN 2088-5555 EXPERT Vol. 11 No. 2 
g. Peramalan untuk bulan 7, yaitu:

$$
\begin{aligned}
\mathrm{F}_{\mathrm{t}} & =\mathrm{F}_{(\mathrm{t}-1)}+\alpha\left(\mathrm{A}_{(\mathrm{t}-1)}-\mathrm{F}_{(\mathrm{t}-1)}\right) \\
& =89,737+0,9(90-89,737) \\
& =89,973
\end{aligned}
$$

h. Peramalan untuk bulan 8 , yaitu:

$$
\begin{aligned}
\mathrm{F}_{\mathrm{t}} & =\mathrm{F}_{(\mathrm{t}-1)}+\alpha\left(\mathrm{A}_{(\mathrm{t}-1)}-\mathrm{F}_{(\mathrm{t}-1)}\right) \\
& =89,973+0,9(100-89,973) \\
& =98,997
\end{aligned}
$$

i. Peramalan untuk bulan 9, yaitu:

$$
\begin{aligned}
\mathrm{F}_{\mathrm{t}} & =\mathrm{F}_{(\mathrm{t}-1)}+\alpha\left(\mathrm{A}_{(\mathrm{t}-1)}-\mathrm{F}_{(\mathrm{t}-1)}\right) \\
& =98,997+0,9(140-98,997) \\
& =135,89
\end{aligned}
$$

j. Peramalan untuk bulan 10, yaitu:

$$
\begin{aligned}
\mathrm{F}_{\mathrm{t}} & =\mathrm{F}_{(\mathrm{t}-1)}+\alpha\left(\mathrm{A}_{(\mathrm{t}-1)}-\mathrm{F}_{(\mathrm{t}-1)}\right) \\
& =135,89+0,9(145-135,89) \\
& =144,089
\end{aligned}
$$

k. Peramalan untuk bulan 11, yaitu:

$$
\begin{aligned}
\mathrm{F}_{\mathrm{t}} & =\mathrm{F}_{(\mathrm{t}-1)}+\alpha\left(\mathrm{A}_{(\mathrm{t}-1)}-\mathrm{F}_{(\mathrm{t}-1)}\right) \\
& =144,089+0,9(135-144,089) \\
& =135,90
\end{aligned}
$$

1. Peramalan untuk bulan 12, yaitu:

$$
\begin{aligned}
\mathrm{F}_{\mathrm{t}} & =\mathrm{F}_{(\mathrm{t}-1)}+\alpha\left(\mathrm{A}_{(\mathrm{t}-1)}-\mathrm{F}_{(\mathrm{t}-1)}\right) \\
& =135,90+0,9(125-135,90) \\
& =126,09
\end{aligned}
$$

2) Perhitungan Peramalan di Tahun 2021

Pada tahap pertama ini adalah penentuan nilai alpha $(\alpha)$. Pada dasarnya dalam menentukan nilai alpha ditentukan dari rentang 0.1 sampai 0.9 yang akan digunakan untuk menghitung prediksi. Pada penelitian ini menggunakan nilai alpha 0,9 karena nilai tersebut dinilai lebih akurat [10]. Pada tahap kedua adalah menentukan nilai Ft dengan data yang sebelumnya.

Berikut perhitungan peramalan di tahun 2021:

a. Peramalan untuk bulan 1 , ditentukan sebesar nilai actual rill bulan januari 2021 yaitu 120 .

b. Peramalan untuk bulan 2, yaitu:

$$
\begin{aligned}
\mathrm{Ft} & =\mathrm{F}(\mathrm{t}-1)+\alpha(\text { At-1) }-\mathrm{F}(\mathrm{t}-1)) \\
& =90+0,9(90-90) \\
& =90,9
\end{aligned}
$$

c. Peramalan untuk bulan 3, yaitu: $\mathrm{Ft}=\mathrm{F}(\mathrm{t}-1)+\alpha($ At -1$)-\mathrm{F}(\mathrm{t}-1))$ $=90,9+0,9(75-90,9)$ $=76,59$

d. Peramalan untuk bulan 4, yaitu: $\mathrm{Ft}=\mathrm{F}(\mathrm{t}-1)+\alpha($ At -1$)-\mathrm{F}(\mathrm{t}-1))$ $=76,59+0,9(85-76,59)$ $=84,159$

e. Peramalan untuk bulan 5, yaitu: $\mathrm{Ft}=\mathrm{F}(\mathrm{t}-1)+\alpha($ At -1$)-\mathrm{F}(\mathrm{t}-1))$ $=84,159+0,9(95-84,159)$ $=93,9159$

f. Peramalan untuk bulan 6, yaitu: $\mathrm{Ft}=\mathrm{F}(\mathrm{t}-1)+\alpha($ At -1$)-\mathrm{F}(\mathrm{t}-1))$ $=93,9159+0,9(70-93,9159)$ $=72,39159$

g. Peramalan untuk bulan 7, yaitu: $\mathrm{Ft}=\mathrm{F}(\mathrm{t}-1)+\alpha($ At-1) $-\mathrm{F}(\mathrm{t}-1))$ $=72,39159+0,9(60-72,39159)$ $=61,242$

h. Peramalan untuk bulan 8 , yaitu: $\mathrm{Ft}=\mathrm{F}(\mathrm{t}-1)+\alpha($ At-1) $-\mathrm{F}(\mathrm{t}-1))$ $=61,242+0,9(65-61,242)$ $=64,62$

i. Peramalan untuk bulan 9, yaitu: $\mathrm{Ft}=\mathrm{F}(\mathrm{t}-1)+\alpha($ At-1) $-\mathrm{F}(\mathrm{t}-1))$ $=64,62+0,9(50-64,62)$ $=53,262$

j. Peramalan untuk bulan 10, yaitu: $\mathrm{Ft}=\mathrm{F}(\mathrm{t}-1)+\alpha($ At-1) $-\mathrm{F}(\mathrm{t}-1))$ $=53,262+0,9(53,262-53,262)$ $=53,262$

k. Peramalan untuk bulan 11, yaitu:

$$
\begin{aligned}
\mathrm{Ft} & =\mathrm{F}(\mathrm{t}-1)+\alpha(\text { At-1) }-\mathrm{F}(\mathrm{t}-1)) \\
& =53,262+0,9(53,262-53,262) \\
& =53,262
\end{aligned}
$$

1. Peramalan untuk bulan 12 , yaitu:

$$
\begin{aligned}
\mathrm{Ft} & =\mathrm{F}(\mathrm{t}-1)+\alpha(\text { At-1 })-\mathrm{F}(\mathrm{t}-1)) \\
& =53,262+0,9(53,262-53,262) \\
& =53,262
\end{aligned}
$$

Tabel 1. Hasil Perhitungan Prediksi

\begin{tabular}{lrrr}
\hline \multicolumn{1}{c}{ Bulan } & Tahun & Data Actual & Prediksi \\
\hline Januari & 2020 & 120 & 120 \\
Februari & 2020 & 95 & 120,9 \\
Maret & 2020 & 110 & 97,59 \\
April & 2020 & 85 & 108,7 \\
Mei & 2020 & 90 & 87,37 \\
Juni & 2020 & 90 & 89,737 \\
Juli & 2020 & 100 & 89,973 \\
Agustus & 2020 & 140 & 98,997 \\
September & 2020 & 145 & 135,89 \\
Oktober & 2020 & 135 & 144,089 \\
November & 2020 & 125 & 135,90 \\
Desember & 2020 & 100 & 126,09 \\
Januari & 2021 & 90 & 90 \\
Februari & 2021 & 75 & 90,9 \\
Maret & 2021 & 85 & 76,59 \\
April & 2021 & 95 & 84,159 \\
\hline
\end{tabular}




\begin{tabular}{lrrr}
\hline \multicolumn{1}{c}{ Bulan } & Tahun & Data Actual & Prediksi \\
\hline Mei & 2021 & 70 & 93,9159 \\
Juni & 2021 & 60 & 71,39159 \\
Juli & 2021 & 65 & 61,242 \\
Agustus & 2021 & 50 & 64,62 \\
September & 2021 & & 53,262 \\
Oktober & 2021 & & 53,262 \\
November & 2021 & & 53,262 \\
Desember & 2021 & & 53,262 \\
\hline
\end{tabular}

Dari Tabel 2 dapat diperoleh hasil prediksi pada bulan September $=53,262$, Oktober $=53,262$, November $=53,262$, dan Desember $=53,262$.

\section{Kesimpulan}

Dari pembahasan hasil penelitian diatas tersebut yang telah di buat, penelitian ini menyimpulkan bahwa penelitian ini berhasil membuat aplikasi prediksi penjualan kopi dengan metode Single Exponential Smooting untuk mengetahui produk kopi terlaris. Penelitian ini membuat aplikasi ini dengan metode single exponential smoothning dimana metode memerlukan data data sebelumnya untuk menghasilkan data predikdi penjualan selanjutnya. Penelitian ini menguji 3 teori yang digunakan dalam menentukan hasil prediksi penjualan kopi. Teori yang diuji dalam penelitian ini adalah teori penentuan data kopi, data sebelumnya dengan menggunakan pendekatan Single Exponential Smooting. Harapan untuk kedepannya agar aplikasi prediksi berbasis web ini dapat dikembangkan lagi dalam segi fitur ataupun desain yang lebih beragam lagi. Dari hasil penelitian ini dilakukan untuk menghasilkan hasil prediksi beserta metode Single Exponential Smooting, diharapkan dalam penelitian selanjutnya dapat dilakukan perbandingan dengan metode lainnya agar dapat memperbandingkan hasil prediksi akurasi.

\section{Daftar Pustaka}

[1] S. F. Sahat, N. Nuryartono, and M. P. Hutagaol, "Analisis Pengembangan Ekspor Kopi Di Indonesia," J. Ekon. Dan Kebijak. Pembang., vol. 5, no. 1, pp. 63-89, 2018, doi: 10.29244/jekp.5.1.6389.
[2] Badan Pusat Statistik, "Output Tabel Dinamis," Badan Pus. statstik, p. 2012, 2019.

[3] Y. Andika, "Analisis Strategi Promosi Kopi Luwak dalam Meningkatkan Penjualan Produk Menurut Perspektif Ekonomi Islam," Skripsi Fak. Ekon. Dan Bisnis, 2018.

[4] R. Kultivar, R. Evizal, D. A. N. Fembriarti, and E. Prasmatiwi, "Ragam Kultivar Kopi di Lampung," Agrotrop J. Agric. Sci., vol. 5, no. 1, pp. 80-88, 2016.

[5] S. Santoso, Metode forecasting bisnis masa kini dengan minitab dan spss. Jakarta, 2009.

[6] P. Subagyo, forecasting konsep dan aplikasi. Yogyakarta: BPFE-YOGYAKARTA, 2016.

[7] W. Handoko, "Prediksi Jumlah Penerimaan Mahasiswa Baru Dengan Metode Single Exponential Smoothing (Studi Kasus: Amik Royal Kisaran)," JURTEKSI (Jurnal Teknol. dan Sist. Informasi), vol. 5, no. 2, pp. 125-132, 2019, doi: 10.33330/jurteksi.v5i2.356.

[8] M. R. Kusasi, Sistem Informasi Forecasting Berbasis Regression Untuk Prediksi Jumlah Siswa Pendaftar Baru Pada Aussie Center Of English. Lampung, 2014.

[9] S. Reksohadiprodjo, Bussiness Forecasting. Yogyakarta, 2016.

[10] I. Falani, "Penentuan Nilai Parameter Metode Exponential Smoothing Dengan Algoritma Genetik Dalam Meningkatkan Akurasi Forecasting," Comput. Eng. Sci. Syst. J., vol. 3, no. 1, p. 14, 2018, doi: $10.24114 /$ cess.v3i1.8268. 